
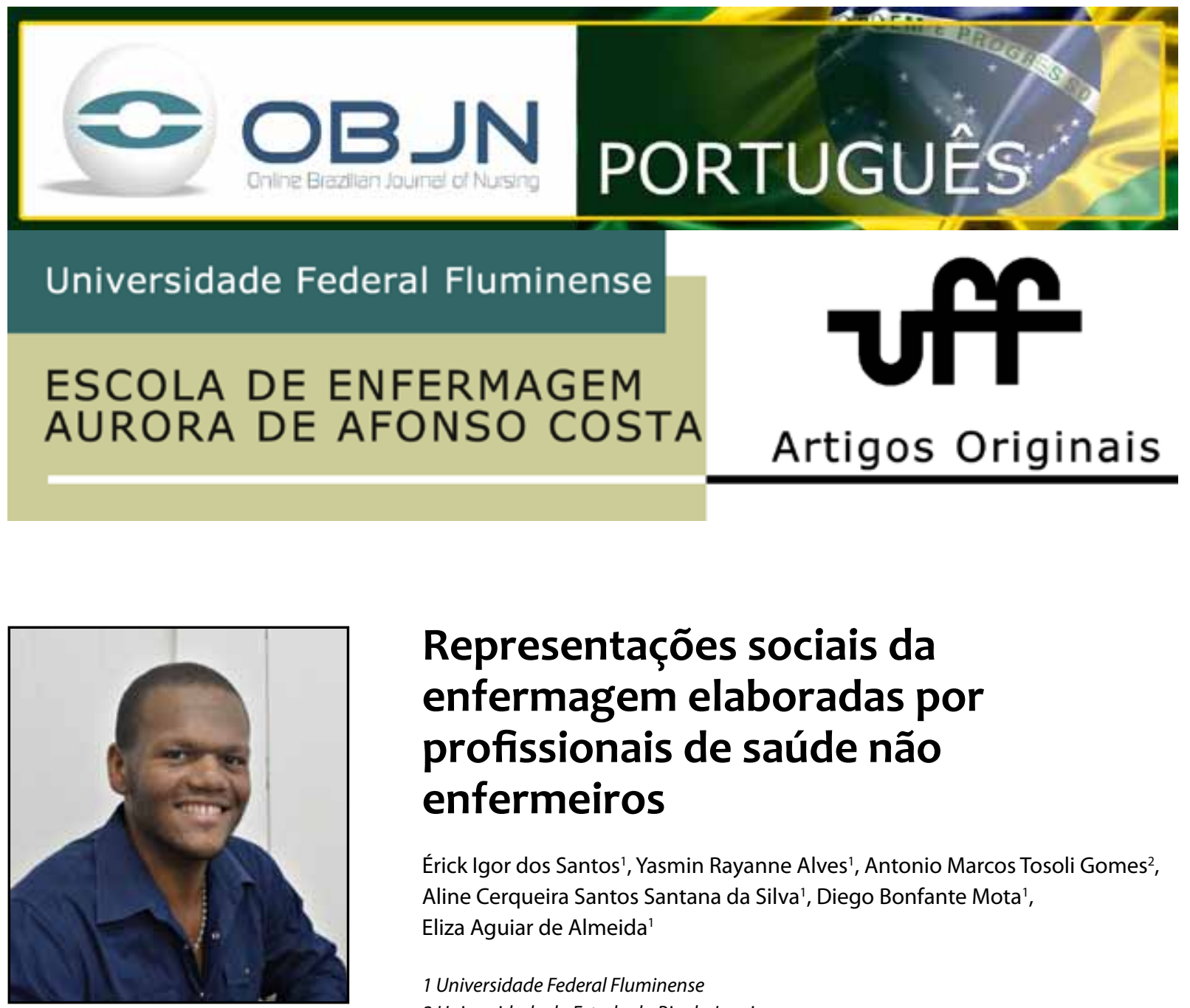

\title{
Representações sociais da enfermagem elaboradas por profissionais de saúde não enfermeiros
}

\author{
Eliza Aguiar de Almeida ${ }^{1}$ \\ 1 Universidade Federal Fluminense \\ 2 Universidade do Estado do Rio de Janeiro
}

Érick Igor dos Santos ${ }^{1}$, Yasmin Rayanne Alves ${ }^{1}$, Antonio Marcos Tosoli Gomes ${ }^{2}$, Aline Cerqueira Santos Santana da Silva', Diego Bonfante Mota',

\section{RESUMO}

Objetivo: analisar as representações sociais da enfermagem para profissionais de saúde não enfermeiros. Método: estudo descritivo, exploratório, de abordagem qualitativa e delineado por meio da Teoria das Representações Sociais em sua abordagem estrutural. Participaram 53 profissionais de saúde não enfermeiros. A técnica de coleta de dados foi a de evocações livres hierarquizadas, utilizando-se o termo indutor "enfermagem". A análise de dados foi por meio do software EVOC 2005. Resultados: figuram no núcleo central da estrutura da representação social da Enfermagem os termos cuidado, equipe, responsabilidade e trabalho. Discussão: identificou-se equilíbrio entre as dimensões funcional, normativa e imagética da representação, que conta com a presença de elementos cognitivos, avaliativos e imagéticos. Há atitude favorável dos participantes com relação ao objeto. Conclusão: trata-se de uma representação que ainda está sendo elaborada, na qual os profissionais recorrem a formas concretas e visíveis de expressar a profissão, para, assim, reconstruir o objeto enfermagem.

Descritores: Enfermagem; Enfermeiras; Autonomia Profissional. 


\section{INTRODUÇÃO}

A enfermagem vem conquistando diversos espaços de atuação profissional no âmbito dos serviços públicos e das instituições privadas. Observa-se a inclusão cada vez maior do enfermeiro em programas de saúde e a sua participação sendo considerada fundamental em estratégias de atenção à saúde da população, permitindo o desenvolvimento de ações como a consulta de enfermagem e a implementação de normas e rotinas nas unidades ${ }^{(1)}$.

No campo da saúde, a autonomia profissional situa-se numa arena de discussões teóricas, metodológicas e políticas que envolvem, de um lado, a tendência do trabalho multi, inter e transdisciplinar, ou seja, a defesa da prestação de assistência aos usuários do Sistema Único de Saúde (SUS) quase que exclusivamente em equipe e fruto do trabalho coletivo ${ }^{(2)}$. Por outro lado, há a premência imposta às profissões da saúde no atual século para que estabeleçam e divulguem sua identidade profissional, colocando em evidência suas especificidades, potencialidades e limites de atuação e de tomada de decisão, sob pena de sofrer sérios prejuízos por sua eventual inércia ${ }^{(2)}$. Aquelas que não o fazem tendem a desaparecer no conjunto total de campos do saber que já possuam tradição histórica ou mesmo aqueles que sejam emergentes, mas que atendam com eficácia e rapidez às necessidades sociais vigentes ${ }^{(3)}$.

Entende-se por expressão da autonomia profissional do enfermeiro quando o profissional, dotado de independência moral e intelectual, usufrui da capacidade de se governar pelos próprios meios e toma decisões da maneira mais livre possível, estabelecendo, no solo do conhecimento técnico-científico, sua prática individual ou coletiva ${ }^{(3-4)}$.

Parte-se do pressuposto que, no contexto da convivência hospitalar, há atribuição de sentido sobre enfermagem, enfermeiro e sua autonomia profissional por profissionais de saúde, enfermeiros e não enfermeiros, bem como por pacientes que experienciam a assistência de enfermagem. Defende-se, portanto, que a enfermagem é um objeto de representação social atrelado a outros, por gerar um corpo de conhecimentos, saberes, afetividades, atitudes e práticas relacionados ao enfermeiro, sua identidade profissional, poder de decisão e liberdade de atuação, portanto também à sua autonomia profissional ${ }^{(4)}$.

A partir destas considerações definiu-se, como questão norteadora, quais as representações sociais da enfermagem para profissionais de saúde nãoenfermeiros. Como objetivo, buscou-se analisar as representações da enfermagem sob a ótica de profissionais de saúde não enfermeiros.

Este estudo mostra-se relevante por possibilitar reflexões e discussões sobre o tema. Poderá, em adição, contribuir para a compreensão sobre a visibilidade da enfermagem, sobretudo do enfermeiro, seu trabalho e seus resultados obtidos ao longo do tempo ${ }^{(6-7)}$. O produto obtido desses debates pode se configurar como um auxiliador no desenvolvimento de ferramentas didático-pedagógicas que facilitem o processo de ensino em enfermagem, o que trará reflexos no trabalho individual ou em equipe.

O investigar da enfermagem em nível psicossocial mostra-se capaz de fornecer os substratos para aumentar sua visibilidade e provocar transformações na prática assistencial ${ }^{(8-9)}$.

\section{MÉTODO}

Trata-se de um estudo descritivo, exploratório, de abordagem qualitativa e delineado por meio da Teoria das Representações Sociais em sua abordagem estrutural(8,10-11). 
A pesquisa foi realizada em uma instituição hospitalar pública municipal de média e alta complexidade localizada na Região dos Lagos do estado do Rio de Janeiro. A instituição conta com maternidade, clínica médica, clínica obstétrica, clínica cirúrgica, pediatria, unidade de terapia intensiva, centro cirúrgico e central de material esterilizado.

À época da coleta de dados, desenvolviam atividades na instituição 136 médicos, 15 fisioterapeutas, nove nutricionistas, três psicólogos, um fonoaudiólogo, um farmacêutico, sete assistentes sociais, um terapeuta ocupacional, um bioquímico e 47 enfermeiros. Foram incluídas todas as profissões de saúde (exceto enfermagem) que contivessem mais de um profissional, uma vez que é necessário de um participante para que haja a interação social exigida para efetivar as trocas simbólicas, constituindo-se como uma premissa da elaboração de representações sociais ${ }^{(10-11)}$.

Como critérios de inclusão:

a) possuir o título de graduação em qualquer área da saúde, logo, ser profissional de nível superior;

b) atuar como profissional da área de graduação por, no mínimo, seis meses no cenário em questão;

c) ser maior de 18 anos, sem faixa etária limítrofe.

Já os critérios de exclusão foram:

a) presença de limitações cognitivas ou de comunicação que inviabilizassem a coleta de dados;

b) ser estagiário, residente ou outro que não possui vínculo empregatício com a instituição;

c) ser profissional de enfermagem.

A exclusão dos enfermeiros deve-se à natureza do objetivo de estudo, já que, em tese, a produção da discursividade deles sobre sua profissão e prática ocorre de maneira singular justamente pelo fato de serem autênticos representantes da profissão. Assim, optou-se por abordar os profissionais de saúde não enfermeiros disponíveis na instituição e excluir os enfermeiros, uma vez que os últimos gozam de maior intimidade à profissão de enfermagem e desenvolveram seus estudos a partir das premissas teóricas da profissão, o que contaminaria os dados obtidos.

A amostra por conveniência foi definida considerando a totalidade de profissionais por área, a aplicação dos critérios de inclusão e de exclusão, a disponibilidade para participar da pesquisa e o número mínimo de participantes necessários para a recuperação de representações na abordagem estrutural da teoria(10-11).

Efetivamente participaram, por intermédio do questionário sociodemográfico de caracterização dos participantes do estudo e da técnica de evocações livres, nove fisioterapeutas, três psicólogos, oito nutricionistas, seis assistentes sociais e 27 médicos, perfazendo um total de 53 participantes. Serviço social e psicologia foram consideradas profissões vinculadas à área da saúde e, por isso, incluídas na amostra da pesquisa, já que a sua prática profissional no contexto do cenário do estudo possuir caráter tão próximo do enfermeiro quanto as outras. $\mathrm{O}$ objetivo de sua presença, tal como a dos demais profissionais de saúde abordados, é o de se debruçar sobre as diferentes formas de vulnerabilidade dos pacientes e tentar solucioná-las ou minimizá-las. Logo, o serviço social e a psicologia trabalham cotidianamente em parceria com a equipe de enfermagem (de modo geral) e mais especificamente com o enfermeiro, o que proporciona um espaço-tempo de trocas simbólicas favoráveis à elaboração de representações ${ }^{(8)}$.

Em observância às determinações da Resolução n466 de 12 de dezembro de 2012, do Conselho Nacional de Saúde/Ministério da Saúde, órgão que aponta as diretrizes e normas da pesquisa envolvendo seres humanos, a pesquisa 
foi submetida aos Comitês de Ética em Pesquisa com Seres Humanos (CEPq) da Universidade Federal Fluminense (UFF) e da Universidade do Estado do Rio de Janeiro (UERJ), já que este estudo se configura como um projeto interinstitucional entre ambas as universidades. Obteve aprovação sob os pareceres no 924.334 (UFF) e n० 939676 (UERJ).

Foram colhidas evocações livres hierarquizadas com o termo indutor "enfermagem". Essas evocações permitiram colocar em evidência a estrutura das representações sociais elaboradas pelos sujeitos sobre o objeto(10-11). A coleta de dados ocorreu entre março e abril do ano de 2015.

A partir da aplicação da técnica de evocações livres, em um primeiro momento foi solicitado a cada participante $(n=53)$ que evocasse cinco palavras ao termo indutor "enfermagem" e, em seguida, que hierarquizasse os termos evocados, em ordem de importância para eles.

A análise do material coletado consistiu, numa primeira etapa, em padronizar os termos evocados que expressavam o mesmo significado para que o software empregado pudesse uní-los e calculá-los de maneira mais fidedigna possível. Em seguida, buscou-se captar o sistema de categorização utilizado pelos sujeitos, permitindo a identificação do próprio conteúdo da representação; para, em uma terceira etapa, reordenar esse conteúdo, evidenciando a sua estrutura subjacente. Para isto, foi utilizado o software EVOC 2005 - Ensemble des programmes permettant l' analyse des evocations, que calcula e informa a frequência simples de ocorrência de cada palavra evocada, a média de ocorrência de cada palavra por ordem de evocação, e a média das ordens médias ponderadas do conjunto dos termos evocados (OME) ${ }^{(11-12)}$.

A apresentação dos dados foi realizada por intermédio da técnica do Quadro de Quatro Casas, que considera a frequência e a ordem média das evocações produzidas. O qua- dro de Quatro Casas é estruturado por meio de quatro conjuntos de elementos. Aqueles localizados no quadrante superior esquerdo correspondem aos possíveis elementos nucleares da representação, compreendendo os elementos possivelmente mais significativos sob a ótica dos sujeitos do estudo. Os elementos localizados no quadrante inferior esquerdo conformam os elementos da zona de contraste da representação, que são elementos de baixa frequência, mas que possuem baixa ordem média de evocação, ou seja, são prontamente evocados. Já no quadrante superior direito estão os elementos que possuem alta frequência, apesar de serem menos prontamente evocadas. No quadrante inferior direito estão os elementos de segunda periferia, menos frequentes e menos prontamente evocados, o que significa dizer que são, provavelmente, os elementos mais periféricos e afastados do núcleo da representação(11-12).

Segundo a abordagem estrutural e a teoria do núcleo central das representações sociais, o quadro de quatro casas se divide em dois sistemas distintos - um central e outro periférico. $\mathrm{O}$ sistema central é formado pelo núcleo central; já o periférico, pelos outros três quadrantes. Em síntese, o sistema central atribui estabilidade, organização e sentido à representação identificada. Por outro lado, o sistema periférico é flexível, integra novas informações à estrutura da representação, protege o núcleo central, não necessariamente trata-se de um consenso no interior do grupo e os elementos que lhe são partícipes estão mais voltados à prática e a situações concretas.

Parte-se da premissa teórica da abordagem estrutural da Teoria das Representações Sociais de que os termos que atendam, ao mesmo tempo, aos critérios de possuírem as maiores frequências, bem como serem evocados primeiro lugar (prontamente evocados) teriam uma 
maior importância no pensamento social dos participantes e seriam os prováveis integrantes do núcleo central da representação(11-12).

\section{RESULTADOS}

Os participantes são, em sua maioria, do sexo feminino (75,5\%), de faixa etária de 25 a 34 anos (41,5\%), professam a religião católica $(45,5 \%)$, com companheiro $(62,3 \%)$, com titulação de mais alto nível de especialista $(81,1 \%)$, de renda média entre $\mathrm{R} \$ 6.000,00$ e R\$ $11.000,00$ (34\%), sem profissional de enfermagem na família $(62,3 \%)$ e relatou já ter atuado profissionalmente junto a enfermeiros nos três níveis de atenção à saúde $(49,1 \%) ; 69,8 \%$ dos participantes relatam já terem sido atendidos por enfermeiros e $56,5 \%$ possuíam acesso a informações sobre enfermagem fora do ambiente laboral. Quando questionados se o enfermeiro possui autonomia profissional, $60,4 \%$ responderam que sim e $39,6 \%$ disseram que não.

Desse modo, para o termo "enfermagem" foram 265 palavras evocadas, dentre as quais 132 eram diferentes. A frequência mínima definida foi de quatro. $A$ frequência média calculada foi de nove e a OME também foi de 3,0. A realização dos cálculos necessários deu-se no próprio software e o quadro de quatro casas (Quadro 1) foi elaborado a partir dos parâmetros definidos acima.

O quadro 1 apresenta uma possibilidade de estrutura representacional para o objeto enfermagem na reconstrução de diferentes profissionais de saúde. O provável núcleo central desta estrutura representacional engloba os termos cuidado, equipe, responsabilidade e trabalho. Percebe-se que este núcleo central apresenta um equilíbrio entre as suas dimensões funcional (cuidado e trabalho), normativa (responsabilidade) e imagética (equipe).
No provável núcleo central é perceptível uma atitude favorável dos sujeitos com relação ao objeto. O termo cuidado, que aponta para uma dimensão cognitiva da representação, indica haver determinado sincronismo entre enfermagem e cuidado, numa analogia que bebe da historicidade da profissão e que a própria profissão, em diversos momentos, legitima. É notória a alta frequência que este termo apresenta no quadro de quatro casas, com o resultado de 27.

$\mathrm{O}$ termo equipe remete a um atrelamento da profissão à sua característica de ser sempre desenvolvida em conjunto, pelo menos na dinâmica do trabalho hospitalar. Outra palavra que figura o provável núcleo central é trabalho, que sinaliza para a elaboração psicossocial de um sentido próprio para a enfermagem, no qual ato de trabalhar possui papel central no tocante à área.

O elemento responsabilidade aponta para uma dimensão normativa e característica avaliativa da representação, atribuindo o adjetivo de responsável àqueles que desenvolvem a profissão de enfermagem.

A chamada zona de contraste, ou a casa inferior à esquerda, possui os termos branco, dedicação, importante, paciente, injeção, profissão e respeito. A dimensão funcional se desdobra neste quadrante no léxico paciente, que é o alvo do cuidado de enfermagem e do trabalho do enfermeiro e de sua equipe. A dimensão imagética refere-se ao branco, palavra de baixa OME, portanto a mais prontamente evocada entre profissionais de saúde em seu representar sobre enfermagem. O branco liga-se à tradicional cor usada pelos profissionais, símbolo de sua higiene física, sua assepsia no trato dos objetos hospitalares e sua pureza diante do sofrimento e da morte; ao mesmo tempo, liga-se à injeção que, embora se constitua como uma força de trabalho e uma ação/procedimento de enfermagem, aqui se resgata como uma das imagens 
Quadro 1 - Estrutura da representação social da enfermagem para profissionais de saúde não enfermeiros. Rio das Ostras, 2015.

\begin{tabular}{|c|c|c|c|c|c|c|}
\hline O.M.E. & $<3$ & & & $\geq 3$ & & \\
\hline Freq. Med. & Termo evocado & Freq. & O.M.E. & Termo evocado & Freq. & O.M.E. \\
\hline \multirow{4}{*}{$\geq 9$} & Cuidado & 27 & 2,296 & & & \\
\hline & Trabalho & 13 & 2,385 & & & \\
\hline & Responsabilidade & 11 & 2,818 & & & \\
\hline & Equipe & 9 & 2,111 & & & \\
\hline \multirow{7}{*}{$<9$} & Paciente & 7 & 2,571 & Hospital & 5 & 3,000 \\
\hline & Dedicação & 6 & 2,167 & Ajuda & 4 & 3,250 \\
\hline & Profissão & 5 & 2,600 & Amor & 4 & 3,250 \\
\hline & Respeito & 5 & 2,800 & \multirow[t]{4}{*}{ Medicação } & \multirow[t]{4}{*}{4} & \multirow[t]{4}{*}{3,250} \\
\hline & Branco & 4 & 1,750 & & & \\
\hline & Importante & 4 & 2,750 & & & \\
\hline & Injeção & 4 & 2,000 & & & \\
\hline
\end{tabular}

Fonte: autoria própria

mais difundidas do enfermeiro na sociedade, em revistas, novelas, filmes e desenhos animados, materiais de divulgação da própria profissão, de hospitais e de escolas de formação profissional. Por fim, o léxico profissão fornece a imagem de uma determinada inserção social e institucional, que é o aspecto profissional da enfermagem.

A dimensão normativa mostra-se presente nas palavras dedicação e respeito, dois elementos que expressam posicionamento favorável, e que dizem respeito a uma forma da enfermagem se concretizar no cotidiano das instituições de saúde e possui suas raízes na história da profissão e em sua interface com a religião cristã e a sua ancestralidade nos cuidados prestados pelas mulheres à sua fa- mília e aos seus filhos. Simultaneamente, essa dimensão normativa relaciona-se também à atitude humana diante do sofrimento, do processo de adoecimento e de morte de outro ser humano, lugar na qual são recomendadas a empatia, que se concretiza no respeito, e a dedicação na manutenção e no cuidado do bem maior que se pode ter - a vida.

O termo importante refere-se a uma dimensão atitudinal positiva da profissão por parte dos participantes do estudo, cujo posicionamento favorável já se mostrou evidente no provável núcleo central.

A evocação paciente reforça o sentido atribuído à enfermagem, pois, para os participantes do estudo, se constitui como a finalidade do trabalho. 
Os termos profissão e injeção, fortemente imagéticos, destacam o caráter laboral da enfermagem, que no passado já foi exercida por leigos e religiosos sem preparo acadêmico. $\mathrm{O}$ termo injeção, por seu turno, reforça o atrelamento da enfermagem a um instrumento de seu fazer, o que indica hipervalorização de seus procedimentos e práticas, como aplicar injeções, por exemplo.

A primeira periferia encontra-se vazia, o que pode ser fruto de um baixo número de sujeitos, e gera baixa dispersão e alta frequência de palavras.

A segunda periferia da estrutura representacional abarca os termos ajuda, amor, hospital e medicação.

Ajuda e amor evidenciam uma dimensão normativa e um caráter afetivo da representação sobre a enfermagem. Percebe-se a permanência de ideias de abnegação e suporte afetivo ao próximo em sua convalescença, historicamente assentadas nas origens religiosas da enfermagem.

Os termos hospital e medicação, elementos imagéticos de maior concretude da segunda periferia, dizem respeito a um dos lócus de trabalho da enfermagem e um de seus procedimentos mais comuns, qual seja a administração de medicamentos.

\section{DISCUSSÃO}

Com base nos pilares éticos e filosóficos da profissão (pautados no amor e na abnegação, por exemplo), não é incomum, entre enfermeiros, a realização de formas de cuidado oficiosas, que buscam superar as limitações impostas por fatores sociais, institucionais ou econômicos. Desta maneira, caso a demanda do paciente exija, esses profissionais podem perceber-se na incumbência de resolver di- lemas provenientes da ausência ou omissão do poder público, apesar da legislação em enfermagem ser precisa sobre os contornos das atribuições do enfermeiro. Por isso, terminando por solucionar ou não a problemática identificada, essas formas de cuidado são invisíveis aos olhos da sociedade e dos demais membros da equipe de saúde, o que prejudica a construção de uma imagem social de resolutividade.

As bases históricas da enfermagem têm o cuidar materno ou familiar como forma direta de manutenção da vida. Possuem ligação, também, com questões religiosas que negavam a relação corpo-espírito, privilegiando o espírito e sua consagração em detrimento do corpo, domínio físico do homem e suscetível às vicissitudes do plano terreno ${ }^{(7,10,12)}$.

A profissão, em sua historicidade, utilizou conhecimentos provenientes do senso comum para definir o seu fazer, mas esta característica tem sido minimizada pela busca contínua pelo aprimoramento teórico e técnico-científico, consubstanciado, sobretudo, pelo desenvolvimento e aplicação das teorias de enfermagem, que representam um importante traço do saber próprio da área(1).

O surgimento das teorias conferiu um rosto intelectual à profissão. Porém, sua aplicação ou o desenvolvimento de novas teorias precisa considerar o contexto mercadológico e o atual perfil dos profissionais que a compõem, a urgência por visibilidade e as contradições do processo de trabalho em saúde.

Procedimentos de enfermagem, antes considerados simples, como mudanças de decúbito, higiene oral, higiene corporal, cuidados com feridas e administração de medicamentos, hoje são avaliados como fundamentais para o paciente, interferindo diretamente na sua recuperação. Se o cuidado é indevidamente realizado, aumentam o 
período de internação e o risco de adquirir infecção hospitalar e outras complicações, e acrescentam-se a esses acometimentos o prejuízo financeiro e os danos à própria equipe de enfermagem. Logo, tais procedimentos vêm ganhando visibilidade tanto para gestores de instituições públicas e privadas, ressaltando a importância do enfermeiro no cuidado ao paciente ${ }^{(15)}$.

O cuidar não se restringe à execução de atividades técnicas, mas envolve o paciente como um todo, com suas histórias, sentimentos e expectativas. Ele deve resgatar a importância dos aspectos emocionais, psicológicos e físicos e valorizar o paciente em todas as suas dimensões ${ }^{(14)}$. O cuidado em saúde também pode ser compreendido como um ato singular que objetiva o bem-estar dos seres envolvidos ${ }^{(15)}$.

A prática profissional do enfermeiro se distingue da dos demais membros da equipe de enfermagem em termos de sustentação teórico-filosófica no processo de cuidar, ensinar e pesquisar. Além disso, a legislação garante que os cuidados de enfermagem sejam de responsabilidade do enfermeiro, devendo ser executados diretamente por ele ou por técnicos da área sob a sua supervisão(16).

Estudos indicam que o insuficiente número de profissionais de enfermagem atinge negativamente o cuidado prestado aos pacientes, proporcionando maiores chances de ocorrência de erros adversos, entre eles os erros no processo da terapia medicamentosa ${ }^{(15)}$.

Os enfermeiros, no contexto de suas responsabilidades, apresentam comprometimento com o saber e o fazer em seu cotidiano. A responsabilidade encontra-se ligada ao conhecimento apropriado pelos profissionais ao longo da vida, no seu trabalho, ou ainda, pela maneira como revisitam analiticamente sua atuação profissional diante das transforma- ções do mundo das ciências, portanto como produto do processo de interação e comunicação ${ }^{(17)}$. Nesse sentido, cabe aos enfermeiros buscar informações atualizadas sobre suas atividades, os problemas existentes com o indivíduo, família e o ambiente ${ }^{(18)}$.

A diversificação das áreas de especialidade em enfermagem amplia as oportunidades de emprego, podendo este ser uma das principais motivações a fazer com que os cursos tenham uma alta demanda. Apesar disto, as instituições de ensino superior precisam preocupar-se em fomentar uma visão ampliada do processo saúde-doença-cuidado que privilegie a segurança e a qualidade do cuidado nas atividades sob a responsabilidade do enfermeiro.

Por isso, alguns dos desafios à formação de novos enfermeiros são o ensino da prática reflexiva, da valorização da práxis da enfermagem, da indissociabilidade entre teoria e prática na enfermagem, da tarefa de liderar sem deixar de estabelecer permanentemente o diálogo, do manejo da ambiguidade entre tecnologia e humanidade presente na assistência de enfermagem, do eixo norteador da profissão de enfermeiro, ou seja, sua essência, e, não menos importante, o caminho político rumo à consolidação da autonomia profissional ${ }^{(19)}$.

Considerando o exposto, o ensinar a ser enfermeiro não deve ser imune às exigências mercadológicas. Frequentemente o mercado de trabalho e o ensino universitário podem diferenciar-se um do outro nas expectativas que depositam sobre os ombros dos enfermeiros recém-graduados. Isto porque se a academia busca a formação de profissionais pensantes e com forte capacidade para exercer sua cidadania, não raramente o interesse do mercado de trabalho está em indivíduos com notável destreza manual, velocidade e 
precisão na execução das tarefas que lhes são atribuídas $^{(20)}$.

Na estrutura da representação foi identificada a escassez de dimensões práticas e afetivas, o que significa que a representação, apesar de já possuir contornos definidos, ainda não se encontra definitivamente estabelecida e está susceptível a abarcar novos elementos de acordo com o contexto em que os sujeitos se inserem. É possível, portanto, que se trate de uma representação não autônoma, pois pode estar atrelada a outros objetos de representação afins. Em paralelo, a presença de elementos que remetem à dimensão imagética da representação mostra-se abundante.

Nota-se a possibilidade de que, em meio ao processo de elaboração de um posicionamento próprio sobre a enfermagem, os sujeitos recorrem a formas concretas e visíveis de expressão da profissão, como injeção, medicação, branco e hospital, para reconstruir o objeto enfermagem por meio de imagens que possuam sentido sobre o objeto de representação. O resultado desta (re) construção do objeto é a formulação de um conhecimento novo a partir da observação e das trocas simbólicas.

\section{CONCLUSÃO}

Conclui-se haver uma atitude positiva dos profissionais de saúde com relação à enfermagem. O provável núcleo central de sua representação social sobre a área apresenta certo equilíbrio entre suas dimensões normativas, funcionais e imagéticas. É importante ressaltar que a enfermagem se trata de um objeto de representação social para ao grupo, mesmo que ainda em desenvolvimento. Isto porque foram identificados os aspectos essenciais a uma representação, quais sejam a dimensão imagética (ou campo representacional), a presença de conhecimentos sobre o objeto (dimensão cognitiva) e o posicionamento do grupo (dimensão atitudinal).

O trabalho em saúde tem adotado múltiplos arranjos nos últimos séculos, tendo a sua centralidade deslocada da figura de um único profissional para o compartilhamento de saberes e corresponsabilização entre todos os envolvidos na ação de assistir/cuidar/atender. Por isso, para que alcance maior visibilidade entre os diferentes membros da equipe de saúde e perante a sociedade de modo geral, cabe a profissão de enfermagem definir suas características próprias, estabelecer o que Ihe é nuclear e demonstrar os resultados que alcança.

O fato dos profissionais serem, em sua maioria, jovens, pode ter sido uma variável importante na origem dos conteúdos representacionais. Esta característica dos participantes do estudo, somado à constatada imaturidade da representação, significa que os participantes do estudo ainda conhecem pouco sobre a enfermagem, o enfermeiro e sua autonomia profissional e se encontram na busca por melhor compreendê-la.

Este estudo, apesar de ter seu objetivo alcançado, possui limitações proporcionadas por sua realização em apenas um único contexto, com baixo número de participantes e a presença de determinado grau de normatividade social, ou seja, os dados foram coletados em um contexto que pode tê-los influenciado. Isto aponta para a possibilidade de que outras ferramentas metodológicas, aplicadas em novas pesquisas, possam ser melhor sucedidas no esmiuçar do objeto proposto.

A partir do conhecimento sobre as representações estabelecidas pelos grupos sociais envolvidos na assistência de enfermagem, será possível repensar o modelo tecnológico de trabalho (e de ensino para o trabalho) 
estabelecendo novas bases teóricas para o ensino superior sobre o processo de cuidar em enfermagem, a partir das necessidades negociadas entre os participantes e as instituições de saúde, com vistas à obtenção de maior grau de visibilidade social positiva para o campo.

\section{REFERÊNCIAS}

1. Santos Él, Alves YR, Gomes AMT, Ramos RS, Silva ACSS, Santo CCE. Representações sociais da autonomia profissional do enfermeiro para profissionais de saúde não enfermeiros. Rev enferm UERJ. 2015; 23(4):481-7.

2. Guevara B, Zambrano GA, Evies A. Worldview in self-care and care of the other. Enferm Global. 2011;10(21):1-7.

3. Honorato EJSA. A interface entre saúde pública e cibercultura. Ciênc saúde coletiva. 2014;19(2):481-5.

4. Santo CCE, Gomes AMT, Oliveira DC, Santos Él. Por um caminho de compreensão da construção da enfermagem: uma revisão integrativa da autonomia profissional. $R$ pesq cuid fundam online. 2011; 2(Ed. Supl.):767-70.

5. Stein-Backes $D$, Stein-Backes $M$, Erdmann AL, Büscher A, Salazar-Maya A. Significado da prática social do enfermeiro com e a partir do Sistema Único de Saúde brasileiro. Aquichán. 2015; 14(4):560-70.

6. Moreno IM, Siles J. Pensamiento crítico em enfermeira: de la racionalidade técnica à la práctica reflexiva. Aquichán. 2014; 14(4):594-604

7. Schoeller SD, Leopardi MT, Ramos FS. Cuidado: eixo da vida, desafio da enfermagem. $R$ enferm UFSM. 2011; 1(1):88-96.

8. Martinez EA, Souza SR, Tocantins FR. As contribuições das representações sociais para a investigação em saúde e em enfermagem. Invest Educ Enferm. 2012; 30(1):101-7.

9. Avila LI, Silveira RS, Lunardi VL, Fernandes GFM, Mancia JR, Silveira JT. Implicações da visibilidade da enfermagem no exercício profissional. Rev Gaúcha Enferm. 2013; 34(3):102-9.
10. Santos Él, Gomes AMT, Oliveira DC. Representações da vulnerabilidade e do empoderamento por enfermeiros no contexto da AIDS. Texto Contexto Enferm. 2014; 23(2):408-16.

11. Lopes BC, Vargas MAO, Azeredo NSG, Behenck A. Erros de medicação realizados pelo técnico de enfermagem na UTI: contextualização da problemática. Enfermagem em Foco 2012; 3(1):16-21

12. Pott FS, Stahlhoefer T, Felix JVC, Meier MJ. Medidas de conforto e comunicação nas ações de cuidado de enfermagem ao paciente crítico. Rev Bras Enferm, Brasília 2013 mar-abr; 66(2): 174-9.

13. Formozo GA, Oliveira DC, Costa TL, Gomes AMT. As relações interpessoais no cuidado em saúde: uma aproximação ao problema. Rev. enferm. UERJ, Rio de Janeiro, 2012 jan/mar; 20(1):124-7.

14. Bellaguarda MLR, Padilha MI, Pereira Neto AF, Pires $D$, Peres MAA. Reflexão sobre a Legitimidade da autonomia da enfermagem no campos das profissões de saúde à luz das ideias de Eliot Freidson. Esc Anna Nery (impr.)2013 abr - jun; 17 (2):369 - 374

15. Lyckhage ED, Pennbrant S. Work-integrated learning - a didactic tool to develop praxis in nurse education. Advances in Nursing Science. 2014; 37(1):61-9.

16. Bayer GLA. Enfermería y el respeto à la autonomía en el ámbito hospitalario: entre la sobreprotección y el descuido. Av Enferm. 2013; 31(1):126-32.

17. Zhu J, Rodgers S, Melia KM. The impact of safety and quality of health care on Chinese nursing career decision-making. J Nurs Manage. 2014; 22(4):423-32.

18. Kayser JW, Cossette S, Alderson M. Autonomysupportive intervention: an evolutionary concept analysis. J Adv Nurs. 2013; 70(6):1254-66.

19. Enns V, Currie $S$, Wang J. Professional autonomy and work setting as contributing factors to depression and absenteeism in Canadian nurses. Nurs Outlook. 2015; 63(3):269-77.

20. Santos El, Gomes AMT, Oliveira DC, Marques SC, Bernardes MMR. Challenges and confrontations in care by nurses: a study of social representations. Online brazj nurs [internet] 2014 Jun [cited jul 31 2015]; 13 (2):207-18. Available from: http:// www.objnursing.uff.br/index.php/nursing/article/view/4365 
Todos os autores participaram das fases dessa publicação em uma ou mais etapas a seguir, de acordo com as recomendações do International Committe of Medical Journal Editors (ICMJE, 2013): (a) participação substancial na concepção ou confecção do manuscrito ou da coleta, análise ou interpretação dos dados; (b) elaboração do trabalho ou realização de revisão crítica do conteúdo intelectual; (c) aprovação da versão submetida. Todos os autores declaram para os devidos fins que são de suas responsabilidades o conteúdo relacionado a todos os aspectos do manuscrito submetido ao OBJN. Garantem que as questões relacionadas com a exatidão ou integridade de qualquer parte do artigo foram devidamente investigadas e resolvidas. Eximindo, portanto o OBJN de qualquer participação solidária em eventuais imbróglios sobre a materia em apreço. Todos os autores declaram que não possuem conflito de interesses, seja de ordem financeira ou de relacionamento, que influencie a redação e/ou interpretação dos achados. Essa declaração foi assinada digitalmente por todos os autores conforme recomendação do ICMJE, cujo modelo está disponível em http://www. objnursing.uff.br/normas/DUDE_final_13-06-2013.pdf

Recebido:20/08/2015

Revisado: 28/04/2016

Aprovado: 28/04/2016 